\title{
Photochemical Treatment of Drosophila APCs Can Eliminate Associated Viruses and Maintain the APC Function for Generating Antigen-Specific CTLs Ex Vivo
}

\author{
Jun Ye $\mathbb{D}^{1},{ }^{1}$ Chunxia Yang, ${ }^{2,3}$ Zeling Cai, ${ }^{3}$ Weixing Shi $\mathbb{D}^{2,3,4}$ and Hong Yu $\mathbb{D}^{1}$ \\ ${ }^{1}$ Department of Laboratory Medicine, Taizhou People's Hospital, Taizhou, Jiangsu Province, China \\ ${ }^{2}$ Shanghai Yuyan Cell Research Company, 3F Building 4 No. 879 Zhongjiang Road, Shanghai, China \\ ${ }^{3}$ Jiangsu CTL Biological Technology Co. Ltd., 9F, G25, Koutai East and Xinyang North Crossroad, CMC, Taizhou, Jiangsu, China \\ ${ }^{4}$ Johnson \& Johnson Pharmaceutical Research and Development, LLC, 3210 Merryfield Row, San Diego, CA 92121, USA
}

Correspondence should be addressed to Weixing Shi; weixingshi@yahoo.com and Hong Yu; yuhongjianglin@163.com

Received 21 March 2018; Revised 24 May 2018; Accepted 12 June 2018; Published 20 September 2018

Academic Editor: Yona Keisari

Copyright (C) 2018 Jun Ye et al. This is an open access article distributed under the Creative Commons Attribution License, which permits unrestricted use, distribution, and reproduction in any medium, provided the original work is properly cited.

Drosophila cells transfected with MHC class I and a number of costimulation molecules including B7.1, ICAM, LFA-3, and CD70 are potent antigen-presenting cells (APCs) for the generation of antigen-specific cytotoxic T cells (CTLs) in vitro. Using Drosophila APCs, CTLs specific for melanoma antigens have been generated in vitro and adoptively transferred to melanoma patients. However, the recent discovery that Drosophila cells can carry insect viruses raises the potential risk of Drosophila APCs transmitting xenogenic viruses to patient CTLs. In this study, we have investigated photoreactive methods to inactivate insect viruses in APC. A clinical grade psoralen compound, 8-MOP (UVADEX) in combination with UVA treatment $\left(5\right.$ joules/ $\left.\mathrm{cm}^{2}\right)$ can be used to inactivate Drosophila cell viruses. UVADEX treatment is sufficient to inactivate insect viruses but does not affect the expression of MHC class I molecules and costimulation molecules on Drosophila APCs. In fact, UVADEX treatment prevents Drosophila APC growth while maintaining APC function. Furthermore, UVADEX-treated Drosophila APCs maintain or have enhanced APC function as determined by enhanced T cell activation, proliferation, and CTL generation. Thus, the use of UVADEX-treated Drosophila APCs may provide a valuable tool for immunotherapy to generate tumor antigen-specific CTLs.

\section{Introduction}

Cancer immunotherapy, a type of treatment that pushes the immune system to attack tumors, has been ranked at the top of the list of scientific achievements in 2013 [1]. An adoptive cell immunotherapy, otherwise known as activated $\mathrm{T}$ cell therapy, has been developed to treat cancer $[2,3]$. Adoptive cell immunotherapy involves activation of the patient's own $\mathrm{T}$ cells to generate cytotoxic $\mathrm{T}$ lymphocytes (CTLs) which can kill tumor cells specifically. CTLs are activated ex vivo by exposing naïve $\mathrm{CD} 8^{+} \mathrm{T}$ cells to antigenic peptide/MHC complexes presented by antigen-presenting cells (APCs) [4]. The binding between TCR on CD8 T cells and peptide/ MHC complexes on APC leads to T cell proliferation and differentiation. Dendritic cells, macrophages, and B cells can all function as APCs. In addition to MHC, the expression of several costimulatory molecules on APC is also crucial for $\mathrm{T}$ cell activation. Once $\mathrm{CD} 8^{+} \mathrm{T}$ cells are activated, they are differentiated into armed CTLs. The armed CTLs are then able to recognize and kill antigen-expressing target cells, such as virus-infected or cancer cells. Traditional antigen-presenting cells can be replaced by artificial antigen-presenting cells for the purpose of activating resting $\mathrm{CD}^{+} \mathrm{T}$ cells into CTLs $[5,6]$. Insect cells, for example, Drosophila cells that are transfected with MHC class I and costimulatory and adhesion molecules, present a high density of peptides/MHC complexes and have been demonstrated as an effective APC system to stimulate naïve CD8 T cells and drive them to develop into effector cells with cytotoxic activity against target cells [7]. Cytotoxicity is specific to the antigen(s) to which the CTLs were immunized against in vitro. 
As more treatments using interspecies biological materials are used, the safety of the patient is of primary concern. The recent discovery that Drosophila cells can carry insect viruses raises the potential risk of Drosophila APCs transmitting viruses to patient CTLs [8]. Current approaches including germicidal ultraviolet radiation, gamma irradiation, beta-propiolactone, alcohol, detergents, aldehydes, alkylating agents, heat, and other treatments to inactivate viruses may potentially alter APC function and CTL generation [9]. These current approaches do not, for example, preserve the native antigenicity, immunogenicity, and cell membrane integrity that is required for antigen-presenting cell function. As an alternative to these approaches, psoralen derivatives and long-wave ultraviolet light treatment can photo-react and irreversibly cross-link viral nucleic acids inside antigen-presenting cells, eliminating viral infectivity [10] while leaving surface molecules relatively unmodified. Psoralens are planar tricyclic compounds consisting of a furan ring fused to a coumarin moiety, furocoumarin [11]. Psoralen is a photochemical drug, which intercalates between the bases of double-stranded regions of DNA and RNA. When ultraviolet A light is absorbed, psoralen makes mono- and diadducts with pyrimidine bases in nucleic acid. Monoadducts and diadducts prevent subsequent nucleic acid replication of both host and pathogen nucleic acids. This thereby eliminates the infectivity of the viruses present in APCs. It has completed phase III clinical studies in the US and Europe for the safety of apheresis platelets with a photochemical process for pathogen inactivation [12].

Here, we demonstrated that UVADEX (8-MOP) treatment, combined with UV-irradiation, is able to inactivate known insect viruses and that UVADEX treatment does not decrease APC function. We generated antigen-specific CTLs by using Drosophila APCs treated with 8-MOP psoralen (UVADEX) which is a member of the psoralen family and long wavelength UVA light ex vivo. Our data show that UVADEX treatment prevents Drosophila cell growth, while cell surface molecule expression is unchanged. The ability of Drosophila cells to activate T cell, induce T cell proliferation, and generate cytotoxic function remains intact following UVADEX treatment. In addition, UVADEX plus UVA treatment inactivated insect viruses by preventing their replication. In this study, we demonstrated that photochemical treatment of Drosophila antigen-presenting cells with UVADEX and UVA ex vivo can eliminate the infectivity of infectious agents and maintain or increase APC function. Thus, UVADEX-treated Drosophila cells may be a useful reagent in developing cancer immunotherapy.

\section{Results}

2.1. Effect of Glutaraldehyde Fixation of Drosophila Cells on APC Function. Previous studies have used Drosophila cells transfected with MHC class I molecule and costimulatory molecules as artificial APCs to generate antigen-specific CTLs for immunotherapy [7]. However, the discovery that Drosophila cells can carry insect viruses raises the potential risk of Drosophila APCs transmitting viruses to patient CTLs. The viral-like particles were identified as Drosophila X virus
(DXV) which is a lytic virus, Drosophila nodavirus (DrNV) and hantavirus pulmonary syndrome-1- (HPS-1-) like virus [8]. Therefore, inactivation of Drosophila viruses is a very important safety concern for CTL immunotherapy using Drosophila APCs. The inactivation of viruses using $0.1 \%$ of glutaraldehyde fixation has been reported before $[13,14]$. The method of glutaraldehyde crosslinking [15] was also initially used to inactivate Drosophila viruses in Drosophila cells. To determine if glutaraldehyde has an effect on Drosophila APC function, CD69 expression, proliferation, and cytotoxicity of CD8 T cells stimulated by glutaraldehydefixed Drosophila APC were assayed. As shown in Figure 1(a), CD69 expression of CD8 T cells stimulated with QL9 loadedfixed Fly cells was decreased with the increased amounts of glutaraldehyde comparing to the antibody isotype control staining (gray area on the left). In addition, increased glutaraldehyde concentration of caused decreased CTL proliferation and cytotoxicity (Figures 1(b) and 1(c)). All results were repeated in another respective experiment (data not shown) suggesting that although glutaraldehyde would presumably prevent Drosophila viral transmission, it is not an effective treatment because it diminishes Drosophila APC function.

2.2. UVADEX Treatment Inactivates Drosophila Viruses. Since the method of glutaraldehyde fixation was unsuitable for maintaining Drosophila APC function while inactivating viruses in Drosophila APCs, we needed to find an alternative method. Previous studies addressing methods for inactivating RNA and DNA viruses have used psoralen treatment and UV irradiation [10, 16]. Psoralen irreversibly binds to virus RNA or DNA when the complex between psoralen and nucleic acid is exposure to UV irradiation. This crosslinking actually prevents virus DNA or RNA replication [17]; we then presumed that UVADEX plus UV treatment of Drosophila cells would both inactivate Drosophila viral activity and preserve APC function. First, we demonstrated that UVADEX treatment can inactivate both insect viral gp64 gene expression and Drosophial viruses. As shown in Figure 2(a) (left panel), baculoviruses were detected by gp64 antibody staining; however, UVADEX treatment inactivates baculoviruses to express gp64 (Figure 2(a), right panel). To determine if UVADEX treatment can inactivate Drosophila viruses, we purified Drosophila viruses from intact Drosophila cells and infected to viral free cell line clone 5-5. The observation is shown visually via microscopy analysis (Figure 2(b)); on the left panel, infected clone 5-5 cells underwent apoptosis while UVADEX treatment inactivates Drosophila viruses. This result was further confirmed by propidium iodide (PI) staining (Figure 2(c)). Since Drosophila viruses contain a Drosophila $\mathrm{X}$ virus which is a lytic virus, we developed a viral infectivity assay to infect clone 5-5 cell line using a serial diluted viral fraction. As shown from one individual experiment in Figure 2(d), infected clone 5-5 cells underwent cell death with the increased dose of the viral fraction. In contrast, UVADEX treatment of viral fractions prevented infection of clone 5-5 indicator cells. The repeated experiment showed the same result (data not shown). 

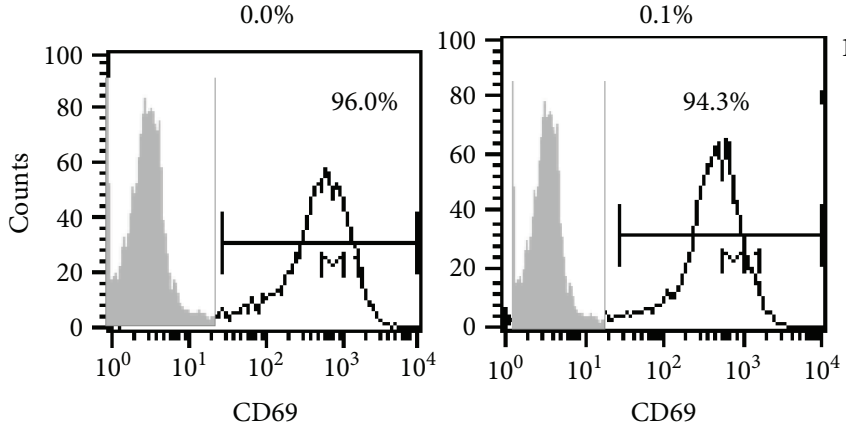

(a)

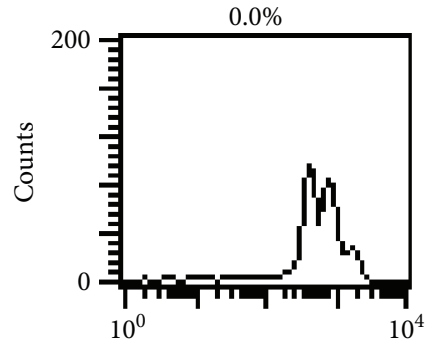

CFSE

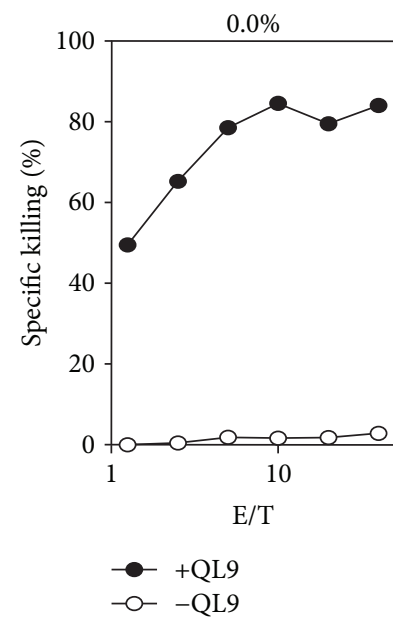

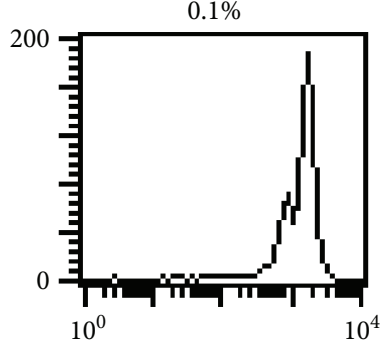

CFSE (b)

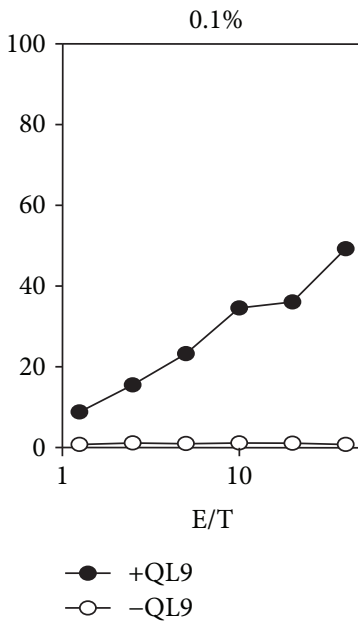

$0.3 \%$
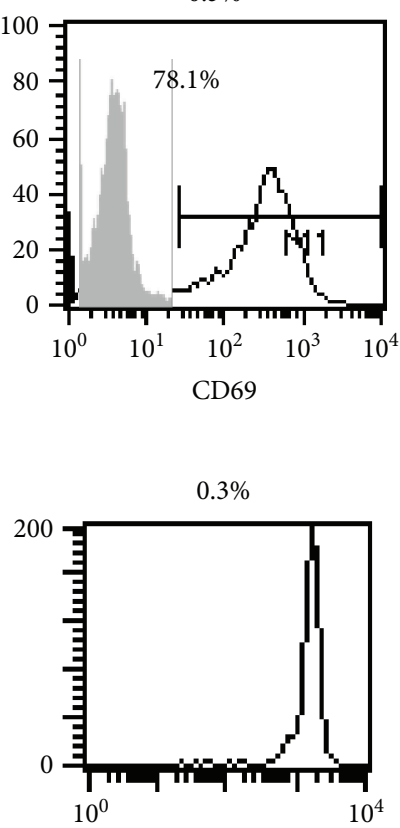

CFSE
$1.0 \%$

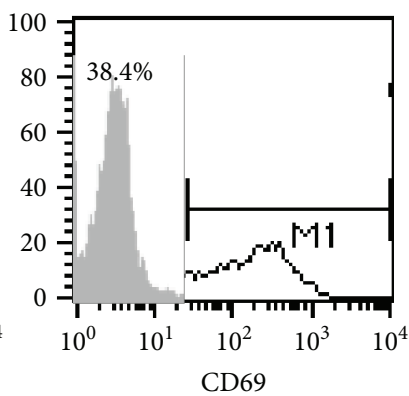

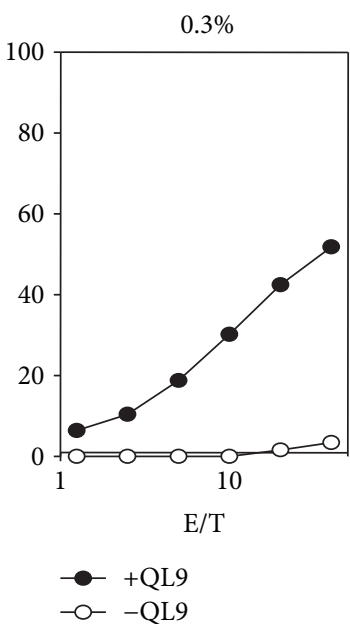

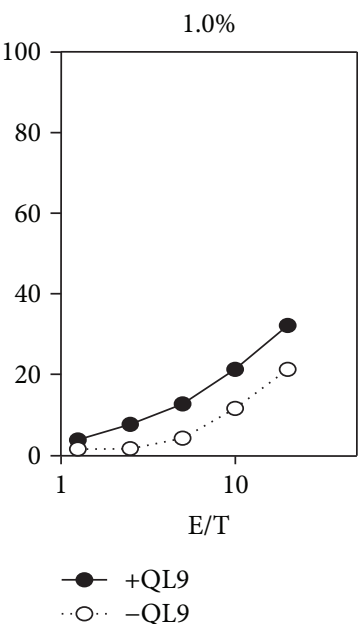

(c)

FIGURE 1: The effect of glutaraldehyde fixation of Fly/L $/ \mathrm{B} 7.1 / \mathrm{ICAM}$ cells on CD8 T cell activation, proliferation, and CTL function. $1 \mathrm{mM}$ $\mathrm{CuSO}_{4}$-induced Fly $/ \mathrm{L}^{\mathrm{d}} / \mathrm{B} 7.1 / \mathrm{ICAM}$ cells were fixed in $2.5 \mathrm{ml}$ of PBS containing $1 \%, 0.3 \%, 0.1 \%$, and $0 \%$ glutaraldehyde at $10 \times 10^{6} / \mathrm{ml}$ at RT for 30 mins, respectively. After completely washing with Drosophila media, the fixed cells were resuspended in $10 \mathrm{ml}$ of MLR (mixed lymphocyte reaction) culture media, one part of cells was loaded with $10 \mu \mathrm{M}$ QL9 peptide at RT for 60 mins. (a) For cell activation, $1 \times 10^{6}$ of purified mouse CD8 T cells were incubated with $1 \times 10^{6}$ of QL9 loaded-fixed Fly cells at $37^{\circ} \mathrm{C}, 5 \% \mathrm{CO}_{2}$ for $16 \mathrm{~h}$. Cells were collected and stained with FITC-conjugated anti-mouse CD69 mAb and antibody isotype control at $4^{\circ} \mathrm{C}$ for 30 minutes. CD69 expression on CD8 cells was analyzed by FACS. (b) For cell proliferation, CD8 cells were labeled with $10 \mu \mathrm{M}$ CFSE at $37^{\circ} \mathrm{C}$ for $15 \mathrm{~min}$. After complete washing with MLR media, $1 \times 10^{6}$ of labeled cells were incubated with $1 \times 10^{6}$ of QL9 loaded-fixed Fly cells at $37^{\circ} \mathrm{C}$, $5 \%$ $\mathrm{CO}_{2}$ for $48 \mathrm{~h}$. Cells were collected and stained with PE-conjugated anti-mouse CD8 mAb at $4^{\circ} \mathrm{C}$ for 30 min. CD8-positive cells were gated from FACS and further analyzed for their green florescence intensity. (c) For the measurement of CTL activity, CD8 T cells purified from three mixtures of spleen cells of $2 \mathrm{c}$ transgenic mice were stimulated with QL9 loaded-fixed Fly cells at $37^{\circ} \mathrm{C}, 5 \% \mathrm{CO}_{2}$ at day 1 , and then propagated in IL-2-supplemented media for 7 days. CTL activity was measured at day 7 by using ${ }^{51} \mathrm{Cr}$ release assay with peptide-pulsed $\mathrm{RmAsL}^{\mathrm{d}}$ target cells (closed dot lines). $\mathrm{RmAsL}^{\mathrm{d}}$ cells without QL9 loading in the assay were a negative control (open dot lines).

\subsection{UVADEX Crosslinking of Drosophila Cell Genomic DNA} Prevents Cell Growth. Next, we wanted to determine if UVADEX crosslinking affected Drosophila viability. The
Drosophila cell line 668 expressing HLA-A2, B7.1, B7.2, ICAM, and LFA-3 was treated with $5 \mu \mathrm{g} / \mathrm{ml}$ of UVADEX and exposed to UVA long wave light $(320-380 \mathrm{~nm})$ for 
-UVADEX

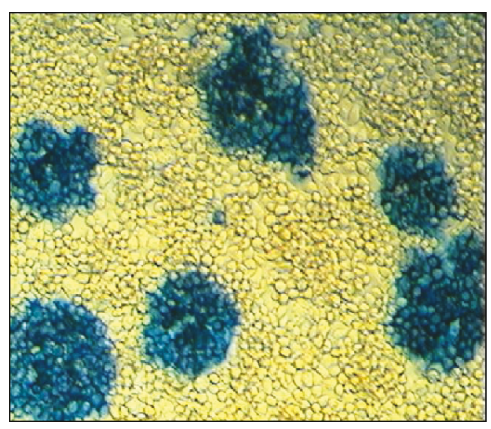

+UVADEX

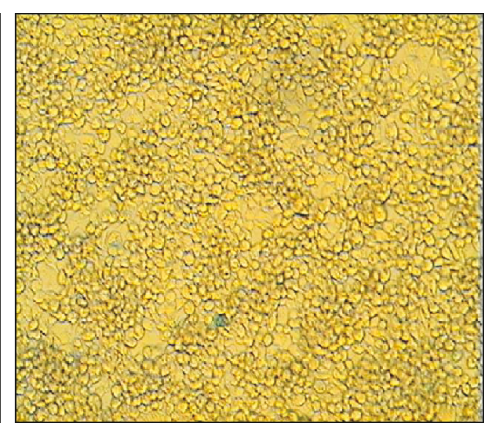

(a)
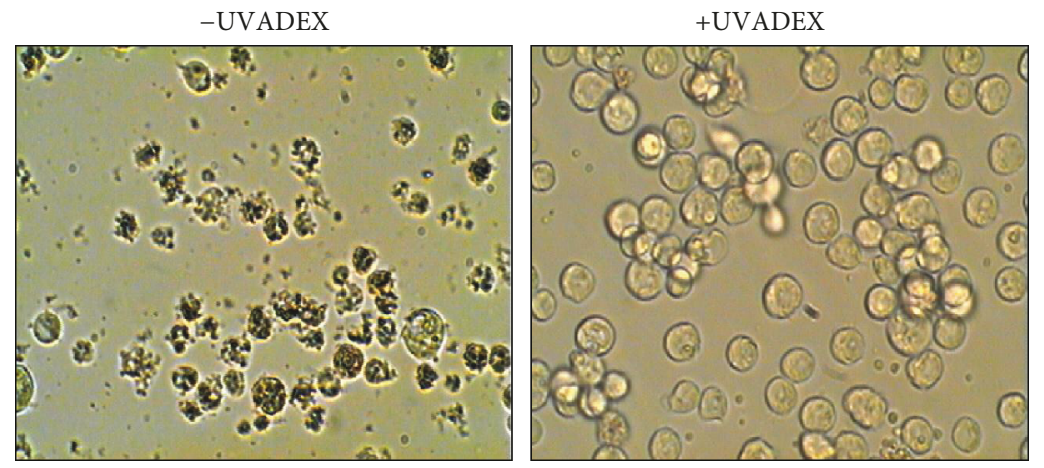

(b)
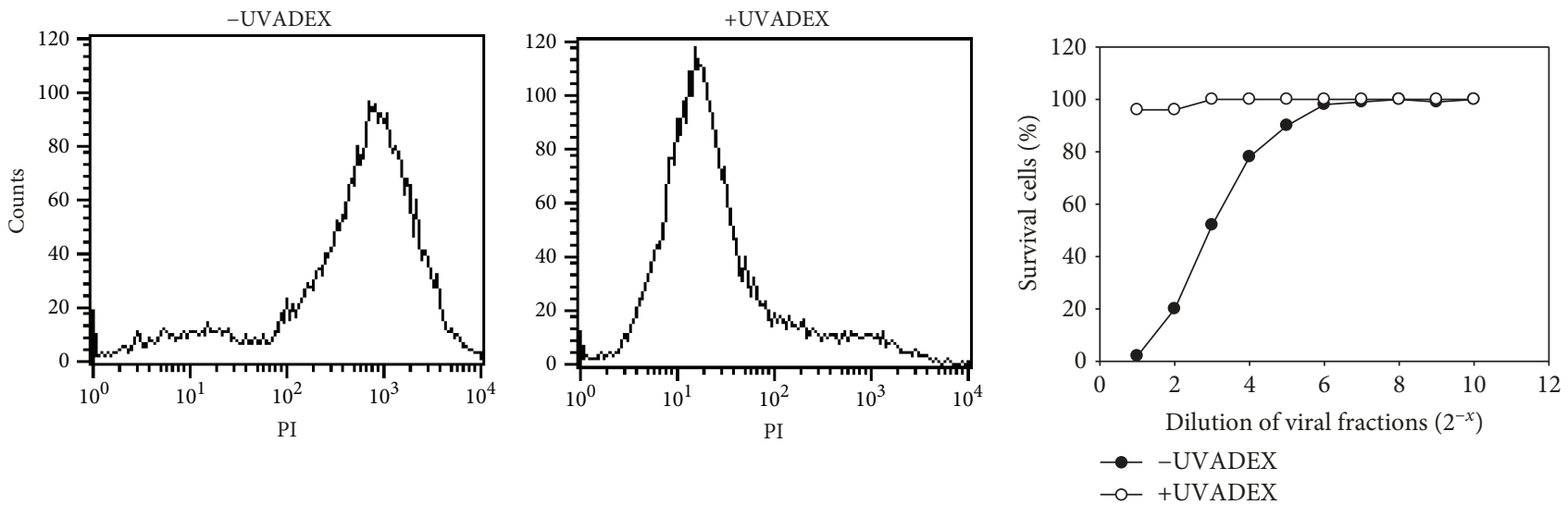

(c)

(d)

FIGURE 2: UVADEX treatment inactivates insect and Drosophila viruses. (a) Baculovirus-infected Sf9 cells were treated with UVADEX for 5 min or left untreated and grown for 4 days. Supernatant from infected cells was collected and used to reinfect Sf9 cells in a 96-well plate. Virus was detected by gp64 antibody staining using a rapid microtiter assay kit (BD BacPAKTM Baculovirus Rapid Titer Kit). Infected cells were pictured under a microscope. Left panel: viral infected cells. Right panel: UVADEX pretreated viral infected cells. (b) Inactivation of virus in Drosophila virus X-infected clone 5-5 cells by UVADEX. Drosophila viral-free cell line clone 5-5 was infected with UVADEX-pretreated or non-treated Drosophila viral fraction at RT for $1 \mathrm{~h}$. The infected cells were washed with PBS completely to remove any residual viral particles and then cultured in media for 3 days. Infected cells were pictured under a microscope. Left panel: viral infected non-UVADEX-treated cells. Right panel: UVADEX-pretreated viral infected cells. (c) PI staining of UVADEX-pretreated or UVADEX-nontreated Drosophila viral fraction-infected clone 5-5 cells at day 3. (d) Drosophila lytic viral-free cell line clone 5-5 was infected with different dilutions of Drosophila viral fraction (1:1 dilution from stock as indicated to $2^{-1}$ ) pretreated with $5 \mu \mathrm{g} / \mathrm{ml}$ of UVADEX plus UV for 10 mins. Infected cells were cultured for 3 days. Cells were collected and stained with PI $\left(1 \mu \mathrm{g} / 1 \times 10^{6}\right.$ cells $)$ at $4^{\circ} \mathrm{C}$ for 10 min to determine the percentage of cell survival cells.

different lengths of time. As shown from one individual experiment in Figure 3(a), UVADEX plus UV treatment inhibited cell growth after as little as 2 minutes of UV exposure $\left(5 \mathrm{~J} / \mathrm{cm}^{2}\right)$ (open dot line). Two weeks after UVADEX treatment, no live cells remained. In contrast, as an experiment control, Drosophila cells not treated with UVADEX remained viable (closed dot line). This result was also repeated from another individual experiment (data not shown). Another widely used method to inactivate cells is $\gamma$-irradiation treatment. Comparing $\gamma$-irradiation of 


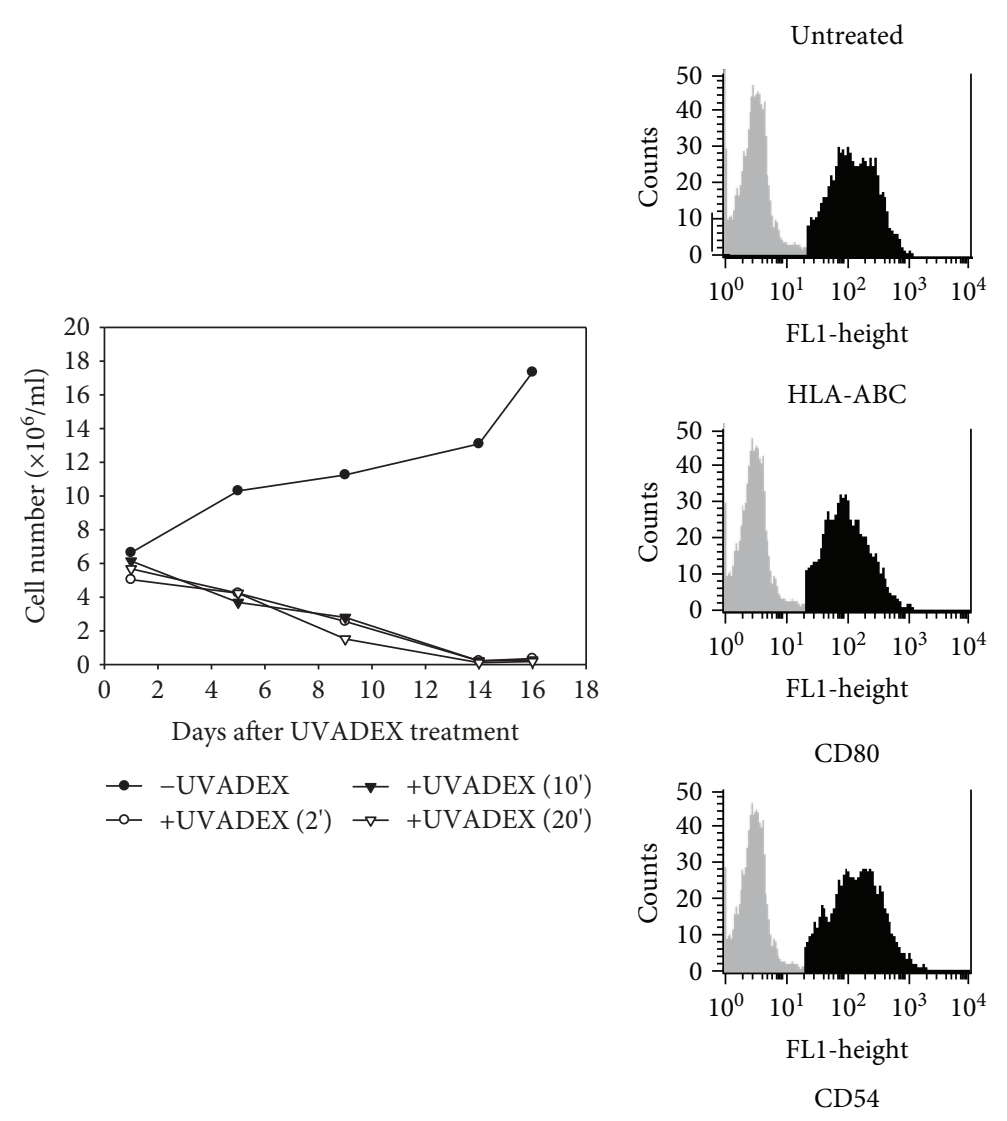

(a)
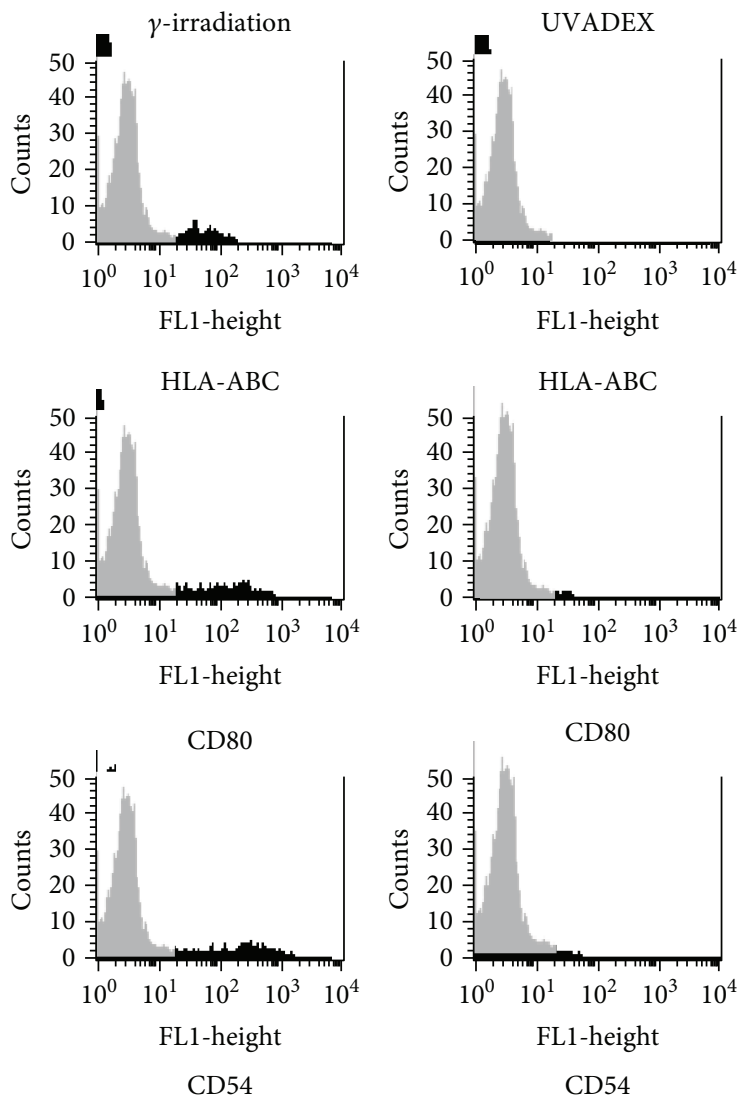

(b)

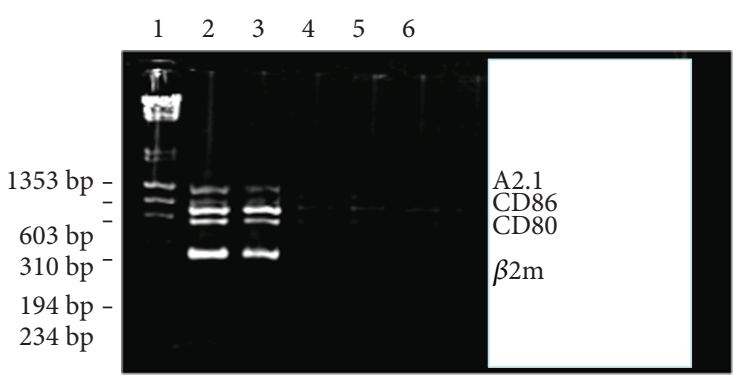

(c)

FIgURE 3: Effect of UVADEX on Drosophila cell growth and surface marker expression. (a) Drosophila cell line 668 was treated with UVADEX $(5 \mu \mathrm{g} / \mathrm{ml})$ at $4^{\circ} \mathrm{C}$ for $30 \mathrm{~min}$ following UV treatment for $0 \mathrm{~min}, 2 \mathrm{~min}, 10 \mathrm{~min}$, and $20 \mathrm{~min}$, respectively. The treated cells were washed completely to remove residual UVADEX and seeded in a 6-well plate at $1 \times 10^{6} / \mathrm{ml}$ and continually grown for 16 days. Cell survival was monitored by trypan-blue staining. (b) UVADEX treatment completely inactivates Drosophila cells. Drosophila cell 668 was treated with UVADEX $(5 \mu \mathrm{g} / \mathrm{ml})$ at $4^{\circ} \mathrm{C}$ for $30 \mathrm{~min}$ or $\gamma$-irradiation for $45 \mathrm{~min}$. The UVDEX-treated cells and $\gamma$-irradiated cells were continually grown for 16 days, respectively. The cells from two different treatments were collected and stained with FITC-conjugated mAb against HLA-ABC, CD80, and CD54 isotype control antibody and PI at $4^{\circ} \mathrm{C}$ for $30 \mathrm{~min}$, respectively. Flow cytometry analysis was used to analyze the live cells to determine the expression of HLA-ABC, CD80, and CD54. (c) RNA was isolated from each group of cells above, and RT/PCR was performed using Platinum Taq Polymerase and specific primers for human beta-2-microglobulin, human LFA-3, human CD80, human CD86, and human A2.1. PCR products in each group run on 1\% agar. Lane 1, MW marker; lane 2, DNA from Drosophila 668 cell; lane 3, DNA from $\gamma$-irradiated 668 cells; lane 4, DNA from UVADEX-treated 668 cells for 2 min; lane 5, DNA from UVADEXtreated 668 cells for $10 \mathrm{~min}$; and lane 6, DNA from UVADEX-treated 668 cells for $20 \mathrm{~min}$.

Drosophila APCs or UVDEX treatment by the FACS analysis of live cell expression of HLA-ABC, CD80, and CD54 from two different treatments demonstrated that UVADEX completely inactivated Drosophila cells (Figure 3(b), right channel) while the treatment from $\gamma$-irradiation did not inactivate Drosophila cells completely (Figure 3(b), middle channel). The isotype control in this experiment was not changed (gray area). Also, DNA was no longer detectable from UVADEX-treated Drosophila APCs (Figure 3(c), lanes 4-6) indicating that UVDEX treatment of Drosophila APCs may crosslink Drosophila DNA and affect the DNA implication in PCR. The result indicated that UVDEX treatment of 
Drosophila cells completely abolishes transcription and translation of key molecules such as HLA-A2, CD80, and CD86, which may prevent transmission of xenogenic viruses. Thus, UVADEX treatment ensures the safety of Drosophila cells as APCs by inactivating Drosophila viruses. In essence, UVADEX treatment changes Drosophila cells into cellular vesicles, and thus, the definition of a xenotransplantation product no longer applies.

\subsection{UVADEX-Treated Drosophila Cells Retain APC} Function. Next, we wanted to address the question whether UVADEX treatment altered APC function. To answer this question, CD8 T cells were purified from 2C TCR transgenic mice and stimulated with UVADEX-treated or nontreated Drosophila APC Fly/L d/B7.1/ICAM. We analyzed T cell activation, proliferation, and CTL activity to access APC function. A known marker of CD8 T cell activation is the up regulation of cell surface CD69 expression. Thus, we monitored CD69 expression over time of CD8 cells activated with either UVADEX-treated or nontreated APCs. As shown in Figure 4, similar CD69 expression was observed. To access proliferative capacity, CFSE-labeled CD8 T cells were stimulated with treated or nontreated APCs for two days. The results showed that UVADEX treatment does not alter T cell proliferation (Figure 4(b)), as demonstrated by equal CFSE dilution between treated or nontreated groups. To confirm if the proliferation of $\mathrm{T}$ cells is an antigen-specific response, CFSE-labeled CD8 $\mathrm{T}$ cells were stimulated with treated or nontreated another Drosophila APC Fly/D $/$ B $7.1 /$ ICAM for two days. The results showed that the stimulated $\mathrm{T}$ cells were not proliferated at all (data not shown). Finally, we tested the ability of treated and nontreated Drosophila cells to generate CTLs. The results shown in Figure 4(c) demonstrated that T cells stimulated by treated or nontreated APC have similar cytotoxicity. All these repeatable data (data not shown) indicate that UVADEX treatment does not affect Drosophila APC function in our experimental condition since we have shown UVDEX-treated Drosophila APCs still partially survive and will not completely die until two weeks after treatment (Figure 3(c)).

2.5. Expansion of Antigen-Specific CD8 T Cells by UVADEXTreated APCs. Tetramer staining of the TCR on the surface of CTLs reveals the antigen-specific nature of the $\mathrm{T}$ cell. The percentage of peptide-specific CTLs can be enumerated by this method and allows the determination of the specificity of the ex vivo stimulated $\mathrm{T}$ cell preparation. To determine if UVADEX treatment alters the generation of antigenspecific CTLs, the percentage of tetramer-positive CTLs generated in the presence of UVADEX-treated or nontreated APCs was assessed. Figure 5(a) shows that mouse CTLs generated in the presence of UVADEX-treated Drosophila APCs have similar or increased percentage of tetramer-specific CTLs. The control of tetramer staining using $\mathrm{D}^{\mathrm{b}}$-GagL-tetramer shows total negative (data not shown). To confirm that UVADEX treatment is beneficial for immunotherapy treatment, we tested the ability of Drosophila APCs to generate human melanoma-specific CTLs. The naïve human CD8 T cells were stimulated with UVADEX-treated or nontreated
APCs loaded with melanoma Mart-1 peptide (Figure 5(b)). The number of Mart-1-specific CD8 T cells was measured by Mart-1/HLA-specific tetramer staining. The control of tetramer staining using HIV-tetramer shows total negative (data not shown). These data showed that the number of antigen-specific $\mathrm{T}$ cells stimulated by UVADEX-treated APCs was significantly higher $(27.18 \%$ versus $22.61 \%$, $13.04 \%$ versus $5.86 \%$, and $43.33 \%$ versus $20.06 \%$ ). In addition, CTL cytotoxicity was measured in the end of CTL generation protocol ex vivo by ${ }^{51} \mathrm{Cr}$ releasing assay. CTL killing activity is increased significantly in $\mathrm{T}$ cells generated by UVADEX-treated APCs from donors 2 and 3 (Figure 5(c), open dot line, subtracted negative control without peptide loading). These data indicate that in addition to retaining APC function, UVADEX treatment can also enhance APC function in some instances (donors 2 and 3).

2.6. The Effect of UVADEX-Treated APCs and CPG on Generation of Antigen-Specific CTLs. To study the mechanism for enhancing the generation of antigen-specific CTLs by UVADEX treatment, we assume that DNA or RNA/ psoralen complexes by UVADEX treatment may mimic CpG DNA structure to activate Toll-like receptors on CD8 $\mathrm{T}$ cells. To address our assumption, we compared the effect of UVADEX-treated APCs and $\mathrm{CpG}$ on the generation of antigen-specific CTLs. CD8 T cells were stimulated by APCs, UVADEX-treated APC, or APC in the presence of CpG or control oligo GpC for 9 days, and the number of antigenspecific $\mathrm{T}$ cells was determined with tetramer staining (Figure 6). The means (horizontal bars) showed the significant statistics, and control tetramer staining showed total negative (data not shown). The data indicated that both CpG treatment and UVDEX treatment result in the increased percent of OVA tetramer-positive cells indicating an enhancement in generating more antigen-specific T cells.

2.7. MyD88-Dependent Enhancement of Activation of Antigen-Specific CTLs by UVADEX-Treated APC. Since MyD88 is an adapter molecule that is involved in the TLR signaling pathway and TLR-9 binding to CpG is MyD88 dependent, we further confirmed that the enhancement of the activation of antigen-specific CTLs by UVADEXtreated APC is also MyD88-dependent (Figure 7). The error bars showed the significant statistics, and control tetramer staining showed total negative (data not shown). This result showed that no enhancement in generating antigen-specific CD8 T cells from MyD88-/- mice both in UVADEXtreated APC and in the presence of CpG oligo comparing to $\mathrm{CpG}$ and UVADEX treatment effect on CTL generation from normal mice, indicating the role of $\mathrm{CpG}$ and UVADEX-treatment to generate more antigen-specific CTLs, may be through TLR-9.

\section{Discussion}

Drosophila APCs have been demonstrated as effective antigen-presenting cells to stimulate naïve CD8 T cells to generate CTLs in a clinical trial. To reduce the risk of Drosophila viral transmission during CTL generation and 

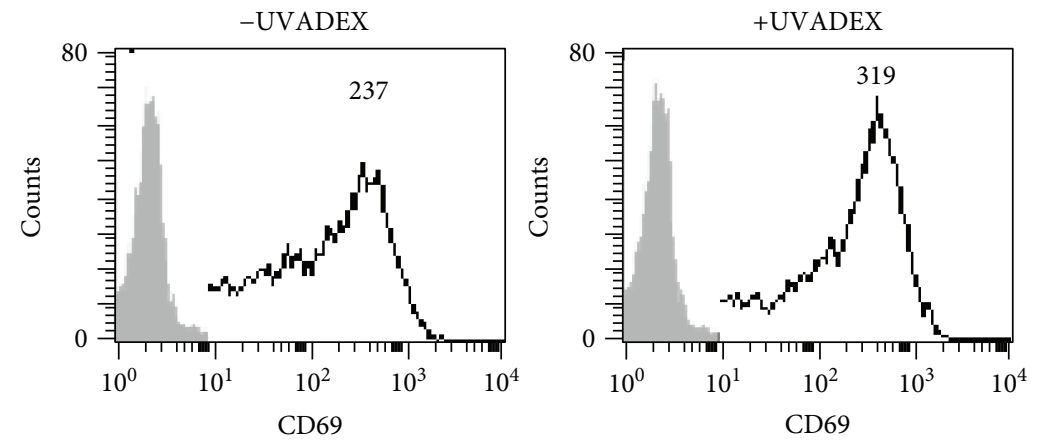

(a)
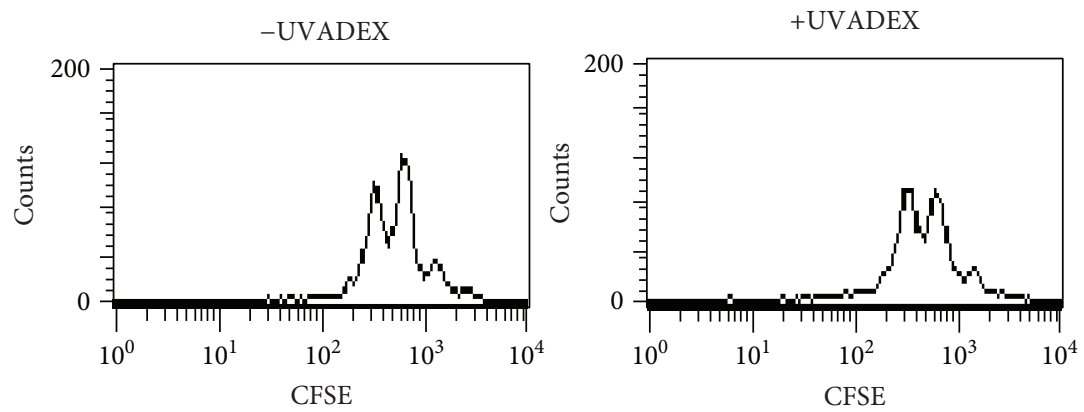

(b)
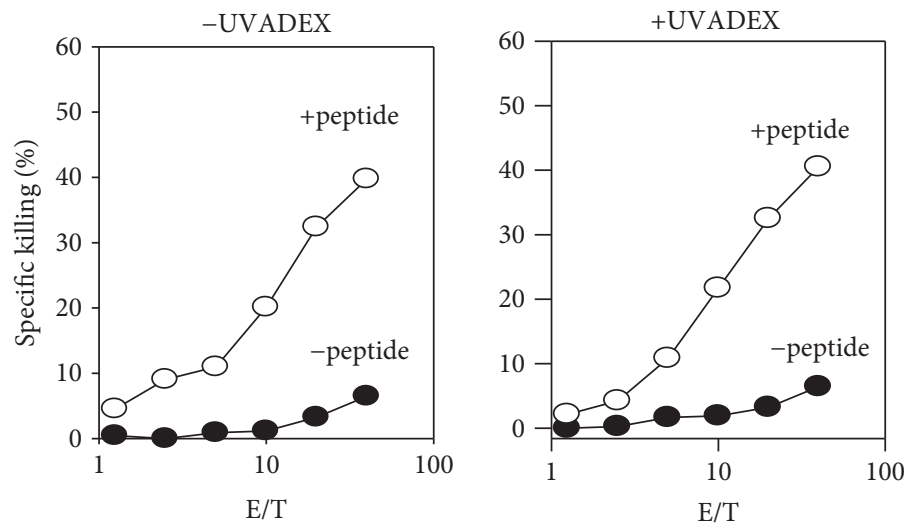

(c)

FIgure 4: UVADEX-treated Drosophila cells retain APC function. (a) CD8 T cells retained CD69 expression when activated by UVADEXtreated Drosophila APCs. Purified CD8 T cells from $2 \mathrm{C}$ transgenic mice were cultured with APCs $\left(\mathrm{Fly} / \mathrm{L}^{\mathrm{d}} / \mathrm{B} 7.1 / \mathrm{ICAM}\right)$ at $37^{\circ} \mathrm{C}$ for $4 \mathrm{~h}$. The cultured cells were collected and stained with anti-CD69-FITC $\mathrm{mAb}$ at $4^{\circ} \mathrm{C}$ and isotype control antibody for 30 minutes and analyzed for CD69 expression by FACS analysis. Left panel: CD8 T cells were stimulated by nontreated APCs. Right panel: CD8 T cells were stimulated by UVADEX-treated APCs. The number in the panel indicated the mean fluorescence intensity by FACS. (b) UVADEXtreated APCs stimulate the proliferation of CD8 T cells as efficiently as untreated APCs. CFSE-labeled CD8 T cells purified from 2C transgenic mice were cultured with APCs in the presence of $10 \mu \mathrm{M}$ of QL9 peptide at $37^{\circ} \mathrm{C}$ for 2 days. The cultured cells were collected and stained with PE-conjugated anti-mouse CD8 mAb at $4^{\circ} \mathrm{C}$ for $30 \mathrm{~min}$. CD8-positive cells were gated from FACS and further analyzed for their green fluorescence intensity. (c) CD8 T cells stimulated with UVADEX-treated APCs retain their cytolytic function. CD8 T cells purified from $2 \mathrm{C}$ mice were stimulated as described in Figure $1(\mathrm{c}) .2 \mathrm{C} \mathrm{CD} 8 \mathrm{~T}$ cells were used in ${ }^{51} \mathrm{Cr}$ release assay with RMAS ${ }^{\mathrm{Ld}}$ target cells.

transfusion, inactivation of Drosophila viruses to get a safety CTL product is a primary concern. The most commonly used methods for viral inactivation are solvent detergent and heat inactivation [18]. However, these approaches have been shown to oblate APC function (data were not shown). We have developed an alternative method using psoralen UV derivatives and long-wave ultraviolet light to inactivate viral nucleic acid inside antigen-presenting cells and eliminate their infectivity, while leaving APC function intact. The psoralen photoreaction provides a potential method for inactivating both known and unknown viruses in active products. Brockstedt et al. developed a class of vaccines by psoralen UV technology, based on killed but metabolically active (KBMA) bacteria, that simultaneously takes advantage of the potency of live vaccines and safety of killed vaccines [19]. 


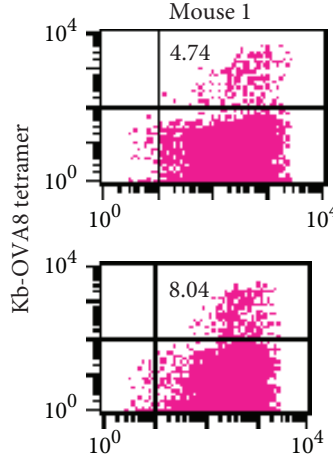

CD8

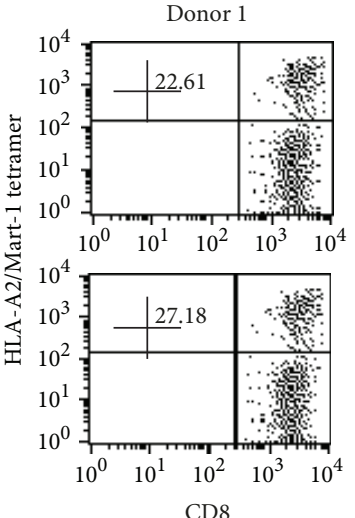

CD8

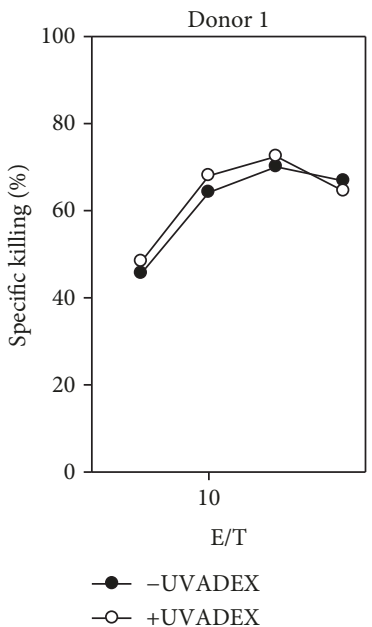

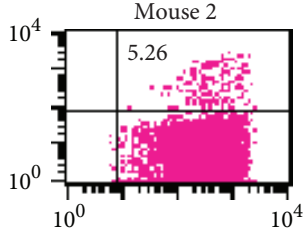
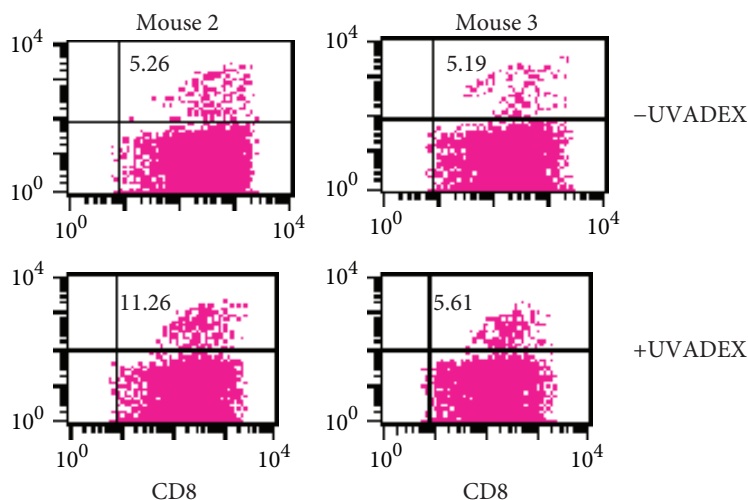

(a)
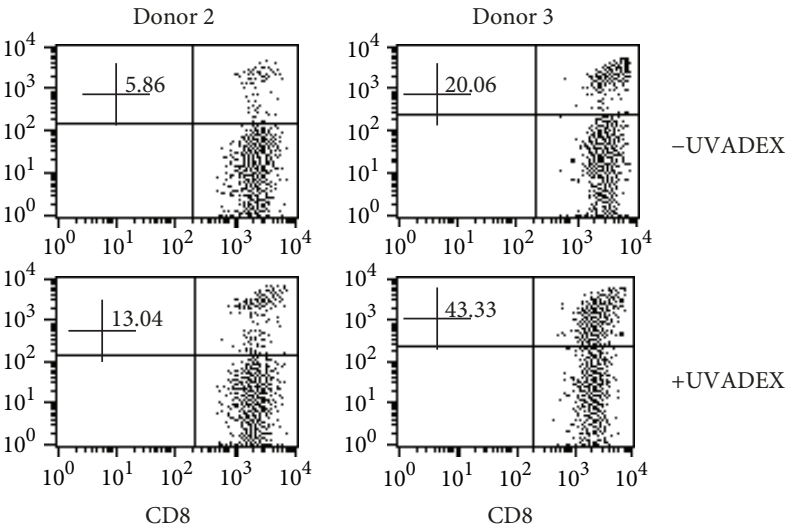

(b)
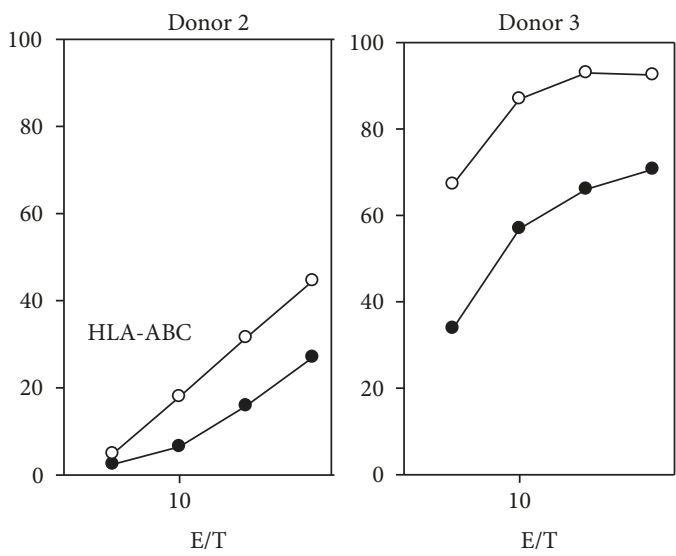

(c)

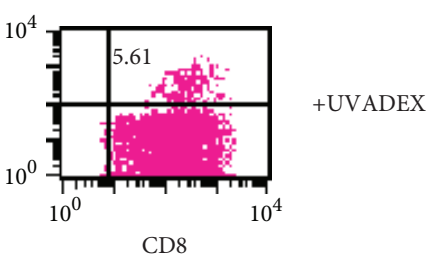




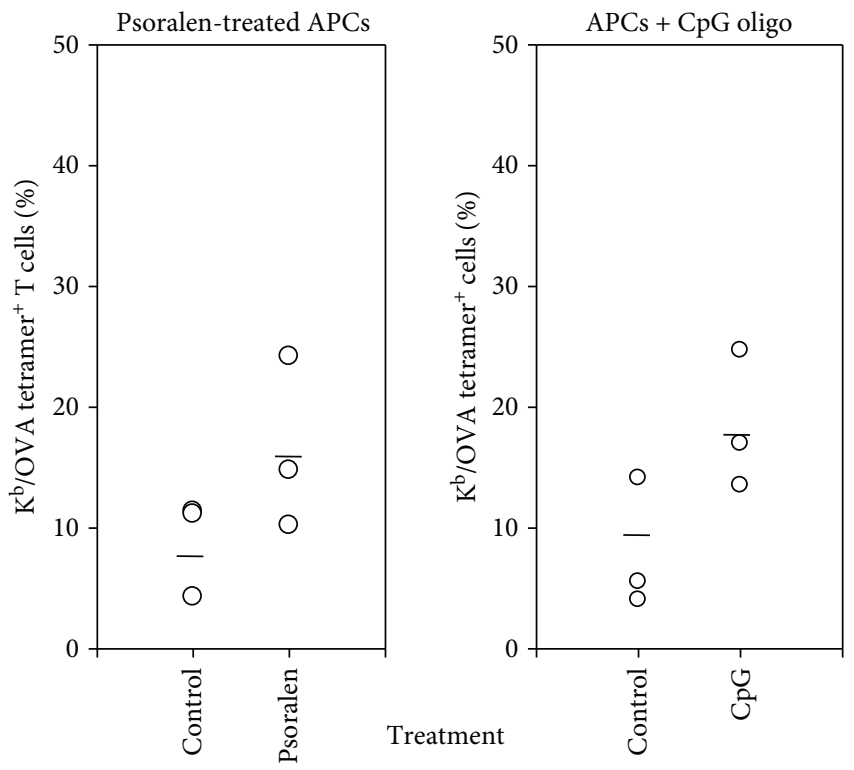

Figure 6: The effect of UVDEX-treated APCs and CpG on the generation of antigen-specific CTLs. CD8 T cells were purified from one pooled B6 spleen and lymph node cells using anti-mouse CD8 beads by AutoMACS (Miltenyibiotech), and three mice were used for the experiment. The purified CD8 T cells were activated on 24-well plates with OVA-peptide-loaded and psoralen UV-treated or nontreated APCs (Fly/ $\left.\mathrm{K}^{\mathrm{b}} / \mathrm{B} 7.1 / \mathrm{ICAM}\right)$ or nontreated APCs in the presence of $5 \mu \mathrm{M}$ CpG oligo or $5 \mu \mathrm{M}$ control oligo (GpC oligo). IL-2 was added at day 3 and day 5, and cells were split at day 7. At day 9, cells were collected and stained with OVA-specific tetramer-PE or D $\mathrm{D}^{\mathrm{b}}-\mathrm{GagL}-$ specific control tetramer and anti-mouse CD8 mAb-FITC at room temperature for $30 \mathrm{~min}$. FACS analysis of OVA-specific CTLs from CD8-positive cells.

8-MOP (UVADEX) is one of the psoralen derivatives commonly being used for the inactivation of a variety of viruses in a blood product. Using the 8 -MOP $(300 \mu \mathrm{g} / \mathrm{ml})$ and UVA treatment $\left(17 \mathrm{~mW} / \mathrm{cm}^{2}\right)$ for 60 minutes inactivated cell-associated HIV-1 in platelet concentrates [19]. Treatment conditions of UVDEX have been optimized for Drosophila APCs to inactivate Drosophila viruses while preserving APC functions. In our experiment, $5 \mu \mathrm{g} / \mathrm{ml}$ of UVDEX and 10 minutes ( $5 \mathrm{~J} / \mathrm{cm}^{2}$ UVA) of UVA treatment are sufficient to inactivate Drosophila viruses (Figure 1(c)). This condition of photoreaction was also sufficient to inactivate baculovirus in an indirect virus detection assay in which Sf9 cells were infected with UVDEX treated or nontreated baculovirus (data not shown). The viral stock obtained from the supernatant of infected cells did not contain infectious virus in UVDEX-treated viral infection where control viral infected Sf9 cells contained a significant amount of PFUs after a single cycle of infection.

For virus inactivation assay, Drosophila virus fractions were prepared from a Drosophila line containing Drosophila viruses and infected to an indicator cell line clone 5-5 that was absent of Drosophila lytic virus DXN. $3 \mathrm{ml}$ of viral fractions prepared from $600 \times 10^{6}$ Drosophila cells was used for infection assay as viral stock solution.

UVDEX treatment of Drosophila cells cultured at $27^{\circ} \mathrm{C}$ did not replicate. Cell counts were negligible after 14 days in culture (Figure 3). The treatment prevented subsequent replication of the Drosophila cells, which remain inactive until they are lysed from lack of growth. This treatment makes Drosophila cells like empty vesical. The UVDEXtreated Drosophila cells were better APCs than untreated
Drosophila cells. The ability to maintain or even enhance the APC function of Drosophila cell line with UVDEX treatment ensures that the Drosophila cells are inactivated prior to exposure to human CD8 T cells. This adds a significant safety feature without diminishing the unique stimulation capacity of the novel APC cells.

The CD8 cells which are specifically stimulated by the UVDEX-treated APC grow as efficiently as those stimulated with nontreated APC. Also, the antigen-specific CTLs generated at the end of the ex vivo culturing cycle are greater than those detected with the untreated APCs. What is the possible mechanism for enhancing antigen-specific CTLs by UVDEX treatment? Recently, the roles of Toll-like receptors in immune recognition and regulation have been broadly studied. Thirteen different TLRs have been identified so far, and some of them recognize molecular patterns such as RNA (TLR3, TLR7, and TLR8), DNA (TLR9), or lipopolysaccharide (TLR4) [20-22]. The interaction between TLRs and their ligands mediates the activation of CD4 and CD8 $\mathrm{T}$ cell response. Gelman et al. presented evidence that TLR ligands directly enhance the survival of activated CD4 T cells [23]. Peng et al. reported TLR-8 mediated reversal of CD4+ regulatory $\mathrm{T}$ cell function [24]. Liu et al. also reported that TLR signals can overcome $\mathrm{T}$ cell tolerance and trigger CD8+ T cell immunity in vitro [25]. In addition, TLR 9, a Toll-like receptor was found in a subset of dendritic cells, B cells, and activated CD4 $\mathrm{T}$ cells [26]. TLR9 recognizes a specific pattern of nucleotides in the DNA, known as $\mathrm{CpG}$ DNA, which is common in bacteria and viruses, but uncommon in human DNA [27]. Using synthetic CpG sequences capable of binding to and activating TLR9, to find an 

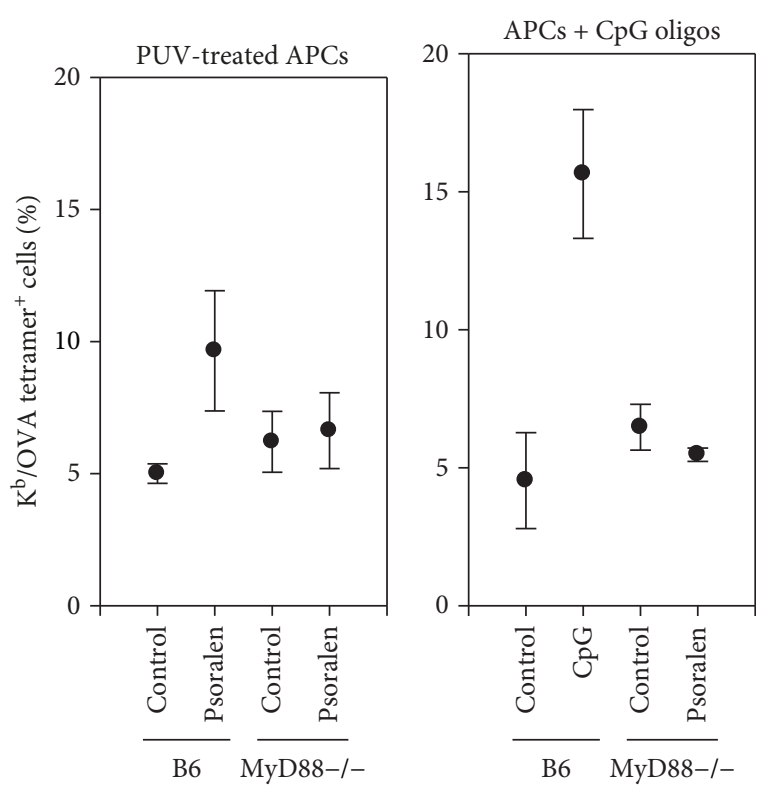

Figure 7: MyD88-dependent enhancement of the activation of antigen-specific CTLs by UVADEX-treated APC. CD8 T cells were purified from one pooled B6 spleen and lymph node cells or one MyD88-/- mouse spleen and lymph node cells by AutoMACS (Miltenyibiotech), respectively. Three B6 mice and three MyD88-/- mice were used for the experiment. The purified CD8 T cells were activated on 24-well plates with OVA-peptide loaded and UVADEX-treated APCs (Fly/K $/$ B7.1/ICAM) or UVDEX nontreated APCs (control for psoralen treatment) or nontreated APCs in the presence of $5 \mu \mathrm{M}$ CpG oligo or $5 \mu \mathrm{M}$ control oligo (GpC oligo). IL-2 was added at day 3 and day 5 , and cells were split at day 7. At day 9, cells were collected and stained with OVA-specific tetramer-PE and or $\mathrm{D}^{\mathrm{b}}$-GagL-specific control tetramer and anti-mouse CD8 mAb-FITC at room temperature for $30 \mathrm{~min}$. FACS analysis of OVA-specific CTLs from CD8-positive cells.

explanation for our observation, we presumed that DNA or RNA/psoralen complexes released from UVDEX-treated Drosophila cells may mimic the $\mathrm{CpG}$ structure to activate Toll-like receptors on CD8 $\mathrm{T}$ cells or some residual nonCD8 cells during CD8 purification to stimulate naïve CD8 $\mathrm{T}$ cells. To confirm that, a parallel in vitro experiment to compare the effect of UVDEX-treated APCs and CpG on the generation of antigen-specific CTLs was performed. The results showed that both UVDEX-treated APCs and the presence of $\mathrm{CpG}$ oligos have an enhancement in generating more antigen-specific $\mathrm{T}$ cells (Figure 6). We further demonstrated that this enhancement in generating antigen-specific CTLs by UVDEX-treated APCs is through the MyD88-dependent pathway (Figure 7).

Elevated programmed death-1 (PD-1) expression can inhibit $\mathrm{T}$ cell activity and is a potential barrier to achieving persisting and optimal immunity via vaccination. A study showed that peptide vaccination with escalating doses of CpG ODN adjuvant yielded higher magnitudes of CD8(+) $\mathrm{T}$ cells with progressively lower PD-1 expression and greater ex vivo function [28]. Another possible mechanism we will include is that DNA or RNA/psoralen complexes released from UVDEX treated Drosophila cells may mimic the CpG structure to facilitate the priming of higher magnitudes of CD8(+) T cells associated with lower expression of PD-1. Future studies will focus on defining the mechanism of psoralen in $\mathrm{T}$ cell activation.

In conclusion, our results describe a new method for CTL generation using an artificial APC system. Drosophila cells are treated with UVDEX plus UVA to prevent cell growth and viral replication. These APCs maintain their ability to generate CTLs, while preventing xenogenic viral transmission. Thus, inactivated UVDEX-treated Drosophila cells provide a clinically feasible system for generating antigen-specific CTLs for immunotherapy.

\section{Materials and Methods}

4.1. Cell Lines. The Drosophila SC2 and insect Sf9 cell lines were purchased from ATCC. The Drosophila APC line 668 expresses HLA-A2, B7.1, B7.2, LFA-3, and ICAM molecules made by scientists in Johnson \& Johnson Pharmaceutical Research and Development, LLC. Drosophila cell line clone 5-5 is a subclone of Drosophila APC line 668 which is Drosophila viral X-free. Drosophila APC lines SC2/L $/ \mathrm{B} 7.1 /$ ICAM and $\mathrm{SC} 2 / \mathrm{K}^{\mathrm{b}} / \mathrm{B} 7.1 / \mathrm{ICAM}$ were prepared and used as described previously [29]. Both 668 and Drosophila APC lines SC2/L $/$ B7.1/ICAM and SC2/K $/$ B7.1/ICAM were cultured in Schneider's Drosophila medium (Invitrogen, San Diego) supplemented with heat-inactivated $10 \%$ fetal bovine serum (Irvine Scientific) and additives, including $50 \mathrm{U} / \mathrm{ml}$ penicillin, $50 \mu \mathrm{g} / \mathrm{ml}$ streptomycin, $2 \mathrm{mM} \mathrm{L}$-glutamine, and $500 \mu \mathrm{g} / \mathrm{ml} \mathrm{G418} \mathrm{(Invitrogen,} \mathrm{San} \mathrm{Diego).} \mathrm{Expression} \mathrm{of}$ transfected molecules was induced by culture for 48 hours in the presence of $1 \mathrm{mM} \mathrm{CuSO}{ }_{4}$. RMAS- $\mathrm{L}^{\mathrm{d}}$ cells engineered to express $\mathrm{H}-2^{\mathrm{d}}$ by transfecting RMAS cells with the $\mathrm{pCDNA}_{3}$ vector encoding $\mathrm{H}-2^{\mathrm{d}}$ gene were provided by $\mathrm{H}$. Eisen (Massachusetts Institute of Technology, Boston, MA). Mammalian cells were grown in RPMI-1640 culture medium (Invitrogen, San Diego) supplemented with heat-inactivated $10 \%$ fetal bovine serum and additives, including $50 \mathrm{U} / \mathrm{ml}$ penicillin, $50 \mu \mathrm{g} / \mathrm{ml}$ streptomycin, and $2 \mathrm{mM} \mathrm{L-glutamine.}$ T2 cells profoundly defective in the presentation of endogenously synthesized antigens to CTL due to a deletion of MHC class II-encoded genes for transporters associated with antigen presentation (TAP1/TAP2) were cultured in RPMI1640 medium supplemental with heat-inactivated $10 \%$ fetal bovine serum.

4.2. Reagents. Recombinant human interleukins IL-2 and IL-7 were purchased from R\&D Systems. FITC-conjugated anti CD69 and phycoerythrin-conjugated anti-CD8 were purchased from BD PharMingen (San Diego, CA). iTAG ${ }^{\mathrm{TM}}$ HLA-A2/Mart-1 Tetramer, iTAG HLA-A2/HIV Tetramer $\mathrm{HIV}$, iTAG $\mathrm{K}^{\mathrm{b}} / \mathrm{OV}$, and iTAG $\mathrm{D}^{\mathrm{b}} / \mathrm{GagL}$ Tetramer were purchased from Beckman Coulter. UVADEX was generously provided by Dr. David Peritt (J\&J, Therakos). Carboxyfluorescein diacetate succinimidyl ester (CFSE) was purchased from Molecular Probes (Eugene, OR). Glutaraldehyde was purchased from Fisher Scientific Co. (50\% biological grade). BacPAK $^{\mathrm{TM}}$ Baculovirus Rapid Titer Kit was purchased from BD Bioscience. 
4.3. Peptides and Oligonucleotides. Peptides used in this study were synthesized on Applied Biosystem model 431 A (Foster City, CA) by standard solid phase peptide synthesis. All peptides were purified with C18 reverse phase HPLC. The concentrations of peptides were determined by quantitative amino acid analysis of HPLC. The sequences of peptides used in this study were as follows: QL9 and QLSPFPFDL [30] and Mart-1, AAGIGILTV, and OVA-8 (SIINFEKL).

4.4. Mice. Male wild-type C57BL/6J mice and MyD88 knock-out (MyD-/-) mice were obtained from The Jackson Laboratory (Bar Harbor, ME). 2C TCR transgenic mice were maintained on a C57BL/6 background and kept under pathogen-free conditions at the rodent breeding colony at the Johnson \& Johnson Pharmaceutical Research and Development (San Diego, CA).

4.5. Preparation of Viral Stock. Drosophila viral fractions were obtained from Drosophila SC cells by sonication of cell pellet and cesium chloride density ultracentrifugation. In detail, $600 \times 10^{6}$ cells were suspended in $0.6 \mathrm{ml}$ insect cell culture media on ice and sonicated for 30 seconds. Cell debris were removed by ultracentrifugation. The collected supernatant was layered on a cushion of cesium chloride density 1.2 $(20 \% w / w \mathrm{CsCl})$ at a ratio of 3 volumes of supernatant for one volume of $\mathrm{CsCl}$ and ultracentrifuged at $100000 \times \mathrm{g}$ for $4 \mathrm{~h}$. The viral fractions were collected from the bottom of the tube, and the density of fractions was measured. Fraction densities between 1.1 to and were pooled in $3 \mathrm{ml}$ volumes and dialyzed against PBS completely.

4.6. UVADEX Treatment of Drosophila APCs. $1 \mathrm{mM} \mathrm{CuSO}_{4}^{-}$ induced insect APC cells were harvested and washed with RPMI-1640/5\% FCS media three times. Cells were resuspended in RPMI-1640/5\% FCS $\left(4 \times 10^{6} / \mathrm{ml}\right)$ including UVADEX $(5 \mu \mathrm{g} / \mathrm{ml}) .3 \mathrm{ml}$ of cells were added to each well in a 6-well plate. The plate was incubated at $4^{\circ} \mathrm{C}$ for $30 \mathrm{mins}$ followed by $10 \mathrm{mins}$ of UV using a UV exposure device (Therakos, J\&J). Following irradiation, cells were collected and washed with MLR (RPMI-1640/10\% FCS) medium three times, resuspended in MLR media $\left(1 \times 10^{6} / \mathrm{ml}\right)$ and then loaded with $10 \mu \mathrm{M}$ peptide at RT for 60 mins.

4.7. Drosophila $X$ Virus Infection Assay. Drosophila viral X-free cell line clone 5-5 was infected with Drosophila viral fraction. 1:1000 diluted Drosophila viral stock was pretreated or nontreated with $5 \mu \mathrm{g} / \mathrm{ml}$ of UVADEX for 10 mins. $1: 1$ serial dilution of this pretreated or nontreated viral stock starting at 1:1000 was used to infect cell line clone 5-5. After completely washing with culture media, infected clone 5-5 cells were cultured for 3 days. $1 \times 10^{6}$ infected cells were collected and stained with PI (Sigma, $1 \mu \mathrm{g} / 1 \times 10^{6}$ cells) at $4^{\circ} \mathrm{C}$ for $10 \mathrm{~min}$. Cell survival was monitored via flow cytometry.

4.8. UVADEX Treatment of Drosophila APCs. Drosophila cells were treated with UVADEX $(5 \mu \mathrm{g} / \mathrm{ml})$ at $4^{\circ} \mathrm{C}$ for $30 \mathrm{~min}$ followed by UV treatment for $0 \mathrm{~min}, 2 \mathrm{~min}, 10 \mathrm{~min}$, and $20 \mathrm{~min}$, respectively. The treated cells were washed completely to remove residual UVADEX and seeded in a 6-well plate at $1 \times 10^{6} / \mathrm{ml}$ and cultured for 16 days. The number of live cells was counted at days 1, 5, 9, 14, and 16 by trypan-blue staining. The UVADEX-treated cells were collected at day 16 and used for DNA extraction, and one aliquot of cells was induced at day 15 and stained with FITC-conjugated mAbs against HLA-ABC, CD80, and CD54 by FACS analysis at day 16.

4.9. Microtiter Assay for Baculovirus Detection. Sf9 cells were infected with stock virus dilution (BD BacPAK Baculovirus Rapid Titer Kit) and were then treated with UV irradiation following psoralen treatment. Cells were washed completely and grown at $28^{\circ} \mathrm{C}$ for 4 days. The culture supernatant was collected from growing cells (Passage One virus stock) at day 5 and reinfected to Sf9 cells seeded in a 96-well plate. The plate was fixed by adding methyl cellulose overlay for $48 \mathrm{~h}$. Immunoassay was used to detect the virus by gp64 antibody staining at day 7 . Stained foci of infection in the highest dilution wells using light microscopy were counted.

4.10. CD8 T Cell Activation and Proliferation Measurement. Purified CD8 T cells $\left(1 \times 10^{6} /\right.$ well $)$ from $2 \mathrm{C}$ transgenic mice were cultured with APCs $\left(1 \times 10^{6} /\right.$ well $)$ expressing $\mathrm{L}^{\mathrm{d}}, \mathrm{B} 7.1$, and ICAM-1 at $37^{\circ} \mathrm{C}$. Cells were collected at the indicated time points. For the analysis of surface CD69 expression, the cultured cells were collected and stained with FITCconjugated anti-CD69 $\mathrm{mAb}$ at $4^{\circ} \mathrm{C}$ for 30 minutes and analyzed on a FACScan (BD, California). Cell proliferation was assayed by CFSE labeling. Briefly, $1 \mathrm{ml}$ of $1 \times 10^{6} \mathrm{CD} 8 \mathrm{~T}$ cells was labeled in $5 \mu \mathrm{M} \mathrm{CFSE}$ at $37^{\circ} \mathrm{C}$ for $8 \mathrm{mins}$ and blocked immediately with FCS ( $2 \%$ final). Labeled cells were spun down and washed twice with PBS/2\% FCS. CFSE-labeled 2C CD8 T cells $\left(1.0 \mathrm{ml}\right.$ at $\left.1 \times 10^{6} / \mathrm{ml}\right)$ were cultured with $1 \mathrm{ml}$ of $10 \mu \mathrm{M}$ of QL9 peptide preloaded APC $\left(1 \times 10^{6} / \mathrm{ml}\right)$ expressing $\mathrm{L}^{\mathrm{d}}, \mathrm{B} 7.1$, and ICAM-1 at $37^{\circ} \mathrm{C}$ for 2 days. The cultured cells were collected and analyzed by flow cytometry.

4.11. Mouse CTL Preparation and Cytotoxic Assay. CD8 T cells were purified from lymph nodes of $2 \mathrm{C}$ transgenic mice using a positive selection MACS system (Miltenyi Biotec). Purified CD8 T cells from 2C transgenic mice were cultured with APCs (SC2/L $/$ B7.1/ICAM) preloaded with $10 \mu \mathrm{M}$ QL9 peptide in a 12 -well plate at $37^{\circ} \mathrm{C}, 5 \% \mathrm{CO}_{2} .20 \mathrm{U} / \mathrm{ml}$ of IL-2 was added at day 3. CD8 $\mathrm{T}$ cells were expanded at day 5 and day 7 , and CTL activity was measured by ${ }^{51} \mathrm{Cr}$ release assay using RMAS- $\mathrm{L}^{\mathrm{d}}$ as target cells at day 9. To prepare targets, RMAS-L ${ }^{\mathrm{d}}$ cells were labeled with ${ }^{51} \mathrm{Cr}(100 \mu \mathrm{Ci} /$ $1-2 \times 10^{6}$ cells) at $37^{\circ} \mathrm{C}$ for $60 \mathrm{~min}$. After labeling, the cells were thoroughly washed and resuspended in RPMI medium with $10 \mu \mathrm{M}$ QL9. The CTL and labeled targets were coincubated at $37^{\circ} \mathrm{C}, 5 \% \mathrm{CO}_{2}$ for $4 \mathrm{~h}$, and the specific lysis was calculated as previously described [31].

4.12. Effects of UVADEX-Treated APCs on the Generation of Antigen-Specific Mouse CTLs. Purified mouse CD8 T cells were incubated in 24-well plates with OVA-peptideloaded and UVADEX-treated APCs (SC2/K $/$ B7.1/ICAM). $20 \mathrm{U} / \mathrm{ml}$ of IL-2 was added at day 3 and day 5. Cells were split at day 7. The expanded cells were collected and stained with OVA-specific $\mathrm{K}^{\mathrm{b}}$-Tetramer-PE at room temperature 
for $30 \mathrm{~min}$ on day 9. FACS analysis of OVA-specific CTLs was used to determine the percentage of antigen-specific CTLs in culture.

4.13. Generation of MART-1-Specific Human CTLs with Untreated or UVADEX-Treated APCs. Drosophila APC line 668 was treated with UVADEX as described above. The APCs were then loaded with $10 \mu \mathrm{M}$ of Mart-1 peptide at room temperature for $4 \mathrm{~h}$. Human CD8 $\mathrm{T}$ cells were purified from HLA-A2 positive PBMC and cultured with Mart-1-peptide-loaded APCs or UVADEX-treated Mart1-peptide-loaded APCs at $37^{\circ} \mathrm{C}, 5 \% \mathrm{CO}_{2}$ for 5 days. Human IL-2 (20 U/ml, R\&D) and IL-7 $(30 \mathrm{U} / \mathrm{ml}, \mathrm{R} \& \mathrm{D})$ were added at day 5 for further culture. The activated CD8 $\mathrm{T}$ cells were restimulated twice at day 7 and day 15 with non-CD8 adherent PBMCs from the same donor in the presence of Mart-1 peptide. The number of antigenspecific CD8 $\mathrm{T}$ cells was identified by Mart-1/HLA-A2 tetramer (Beckman Coulter, CA) staining at day 19.

4.14. Determination of Antigen Specificity by Tetramer Staining. MHC tetramer $(10 \mu \mathrm{l})$ was mixed with the preparation containing the CD8 T cells $\left(10^{6}\right.$ cells in $100 \mu \mathrm{l}$ of FACS buffer). The reagent and cells were incubated at RT for 30 minutes followed by washing in PBS and a low-speed spin $(400 \times \mathrm{g}$ for 5 minutes). The cell pellet was resuspended in FACS buffer $(500 \mu \mathrm{l})$ and immediately read on a FACScan flow cytometry machine.

4.15. Human CTL Cytotoxic Assay. CTL was generated as described above. CTL assay was determined using T2 target cells at day 19 of CTL generation protocol. T2 cells were labeled with ${ }^{51} \mathrm{Cr}\left(100 \mu \mathrm{Ci} / 1-2 \times 10^{6}\right.$ cells $)$ at $37^{\circ} \mathrm{C}$ for $60 \mathrm{~min}$. After labeling, the cells were thoroughly washed and resuspended in RPMI medium with or without $10 \mu \mathrm{M}$ Mart-1 peptide at RT for $1 \mathrm{~h} .{ }^{51} \mathrm{Cr}$-labeled target cells were incubated with CTL in different $\mathrm{E} / \mathrm{T}$ ratios at $37^{\circ} \mathrm{C}, 5 \% \mathrm{CO}_{2}$ for $4 \mathrm{~h}$; the culture supernatant was collected and counted for the calculation of specific lysis.

4.16. $\gamma$-Irradiation Treatment of Drosophila APCs. $1 \mathrm{mM}$ $\mathrm{CuSO}_{4}$-induced APCs were harvested and washed with Drosophila cell culture medium three times. The washed cells were irradiated at 10000 rads using a Gammacell $1000 \gamma$-irradiator machine (Nordion International Inc.). Following irradiation, cells were collected and washed with insect medium three times, resuspended in culture medium $\left(1 \times 10^{6} / \mathrm{ml}\right)$, and then cultured for 40 days. The $\gamma$-irradiated cells were collected at day 40 for DNA extraction, and one aliquot of cells was induced one day before and stained with FITC-conjugated $\mathrm{mAbs}$ against HLA-ABC, CD80, and CD54 by FACS analysis.

4.17. Drosophila DNA Determination by RT/PCR. DNA was isolated from nontreated, UVADEX-treated, or $\gamma$-irradiation-treated Drosophila cells using the Qiagen Blood Amp DNA Kit. A total of $400 \mathrm{ng}$ of DNA from each sample was analyzed by PCR using Platinum Taq Polymerase and vector-specific primers including human beta-2-microglobulin, human LFA-3, human B7-1 (CD80), human B7-2
(CD86), and human A2.1. The PCR protocol consisted of a single stage and 30-cycle amplification using the GeneAmp PCR system 9700 Thermal Cycler. Amplified PCR products including human beta-2-microglobulin (479 bp), human LFA-3 (817 bp), human B7-1 (CD80, 965 bp), human B7-2 (CD86, $1098 \mathrm{bp}$ ), and human A2.1 (1207bp) were loaded on $1 \%$ agarose gel.

\section{Data Availability}

The data used to support the findings of this study are available from the corresponding author upon request.

\section{Conflicts of Interest}

The authors declare that they have no conflicts of interest.

\section{Acknowledgments}

The authors thank Dr. Jill Mooney for helpful discussions and Dr. Ann Moriarty for the review of this manuscript.

\section{References}

[1] J. Couzin-Frankel, "Breakthrough of the year 2013. Cancer immunotherapy," Science, vol. 342, no. 6165, pp. 1432-1433, 2013.

[2] E. N. Baruch, A. L. Berg, M. J. Besser, J. Schachter, and G. Markel, "Adoptive T cell therapy: an overview of obstacles and opportunities," Cancer, vol. 123, no. S11, pp. 2154-2162, 2017.

[3] J. C. Yang and S. A. Rosenberg, "Adoptive T-cell therapy for cancer," Advances in Immunology, vol. 130, pp. 279-294, 2016.

[4] N. P. Restifo, M. E. Dudley, and S. A. Rosenberg, "Adoptive immunotherapy for cancer: harnessing the T cell response," Nature Reviews Immunology, vol. 12, no. 4, pp. 269-281, 2012.

[5] L. R. Neal, S. R. Bailey, M. M. Wyatt et al., "The basics of artificial antigen presenting cells in $\mathrm{T}$ cell-based cancer immunotherapies," Journal of Immunology Research and Therapy, vol. 2, no. 1, pp. 68-79, 2017.

[6] A. L. Siefert, T. M. Fahmy, and D. Kim, "Artificial antigenpresenting cells for immunotherapies," Methods in Molecular Biology, vol. 1530, pp. 343-353, 2017.

[7] C. J. Turtle and S. R. Riddell, "Artificial antigen-presenting cells for use in adoptive immunotherapy," The Cancer Journal, vol. 16, no. 4, pp. 374-381, 2010.

[8] C. L. Webster, B. Longdon, S. H. Lewis, and D. J. Obbard, "Twenty-five new viruses associated with the Drosophilidae (Diptera)," Evolutionary Bioinformatics, vol. 12, Supplementary 2, pp. 13-25, 2016.

[9] K. E. Burnum-Johnson, J. E. Kyle, A. J. Eisfeld et al., "MPLEx: a method for simultaneous pathogen inactivation and extraction of samples for multi-omics profiling," Analyst, vol. 142, no. 3, pp. 442-448, 2017.

[10] K. Schneider, L. Wronka-Edwards, M. Leggett-Embrey et al., "Psoralen inactivation of viruses: a process for the safe manipulation of viral antigen and nucleic acid," Viruses, vol. 7, no. 11, pp. 5875-5888, 2015.

[11] M. M. Melough, E. Cho, and O. K. Chun, "Furocoumarins: a review of biochemical activities, dietary sources and intake, 
and potential health risks," Food and Chemical Toxicology, vol. 113, pp. 99-107, 2018.

[12] J. McCullough, D. H. Vesole, R. J. Benjamin et al., “Therapeutic efficacy and safety of platelets treated with a photochemical process for pathogen inactivation: the SPRINT Trial," Blood, vol. 104, no. 5, pp. 1534-1541, 2004.

[13] E. Marzouk, H. S. Abd El-Hamid, A. M. Awad, K. H. Zessin, E. M. Abdelwhab, and H. M. Hafez, "In vitro inactivation of two Egyptian A/H5N1 viruses by four commercial chemical disinfectants," Avian Diseases, vol. 58, no. 3, pp. 462-467, 2014.

[14] T. Yeargin, D. Buckley, A. Fraser, and X. Jiang, "The survival and inactivation of enteric viruses on soft surfaces: a systematic review of the literature," American Journal of Infection Control, vol. 44, no. 11, pp. 1365-1373, 2016.

[15] A. Dawson, E. Hartswood, T. Paterson, and D. J. Finnegan, “A LINE-like transposable element in Drosophila, the $I$ factor, encodes a protein with properties similar to those of retroviral nucleocapsids," The EMBO Journal, vol. 16, no. 14, pp. 44484455, 1997.

[16] J. Quinn, A. Kessell, and L. Weston, "Secondary plant products causing photosensitization in grazing herbivores: their structure, activity and regulation," International Journal of Molecular Sciences, vol. 15, no. 1, pp. 1441-1465, 2014.

[17] K. Raviprakash, P. Sun, Y. Raviv, T. Luke, N. Martin, and T. Kochel, "Dengue virus photo-inactivated in presence of 1,5-iodonaphthylazide (INA) or AMT, a psoralen compound (4'-aminomethyl-trioxsalen) is highly immunogenic in mice," Human Vaccines \& Immunotherapeutics, vol. 9, no. 11, pp. 2336-2341, 2013.

[18] C. Huangfu, J. Zhang, Y. Ma et al., "Large-scale purification of high purity $\alpha 1$-antitrypsin from Cohn fraction IV with virus inactivation by solvent/detergent and dry-heat treatment," Biotechnology and Applied Biochemistry, vol. 65, no. 3, pp. 446-454, 2018.

[19] D. G. Brockstedt, K. S. Bahjat, M. A. Giedlin et al., "Killed but metabolically active microbes: a new vaccine paradigm for eliciting effector T-cell responses and protective immunity," Nature Medicine, vol. 11, no. 8, pp. 853-860, 2005.

[20] H. Hug, M. Mohajeri, and G. La Fata, "Toll-like receptors: regulators of the immune response in the human gut," Nutrients, vol. 10, no. 2, 2018.

[21] B. J. Ignacio, T. J. Albin, A. P. Esser-Kahn, and M. Verdoes, "Toll-like receptor agonist conjugation: a chemical perspective," Bioconjugate Chemistry, vol. 29, no. 3, pp. 587-603, 2018.

[22] P. Zhang, L. Shao, and J. Ma, “Toll-like receptors 2 and 4 predict new-onset atrial fibrillation in acute myocardial infarction patients," International Heart Journal, vol. 59, no. 1, pp. 64-70, 2018.

[23] A. E. Gelman, J. Zhang, Y. Choi, and L. A. Turka, “Toll-like receptor ligands directly promote activated $\mathrm{CD}^{+} \mathrm{T}$ cell survival," The Journal of Immunology, vol. 172, no. 10, pp. 6065-6073, 2004.

[24] G. Peng, Z. Guo, Y. Kiniwa et al., "Toll-like receptor 8mediated reversal of $\mathrm{CD} 4^{+}$regulatory T cell function," Science, vol. 309, no. 5739, pp. 1380-1384, 2005.

[25] J. Liu, M. Jiang, Z. Ma et al., "TLR1/2 ligand-stimulated mouse liver endothelial cells secrete IL-12 and trigger $\mathrm{CD}^{+} \mathrm{T}$ cell immunity in vitro," The Journal of Immunology, vol. 191, no. 12, pp. 6178-6190, 2013.
[26] S. Norelli, "Could DNA-reactive B lymphocytes be activated through HIV-1 DNA-stimulation involving BCR/TLR-9 pathway to yield antibodies targeting viral DNA?," Medical Hypotheses, vol. 83, no. 6, pp. 659-663, 2014.

[27] W. Zhang, M. An, J. Xi, and H. Liu, "Targeting CpG adjuvant to lymph node via dextran conjugate enhances antitumor immunotherapy," Bioconjugate Chemistry, vol. 28, no. 7, pp. 1993-2000, 2017.

[28] R. M. Wong, K. A. Smith, V. L. Tam et al., "TLR-9 signaling and TCR stimulation co-regulate $\mathrm{CD}^{+} \mathrm{T}$ cell-associated PD-1 expression," Immunology Letters, vol. 127, no. 1, pp. 60-67, 2009.

[29] Z. Cai, A. B. Brunmark, A. T. Luxembourg et al., "Probing the activation requirements for naive $\mathrm{CD}^{+} \mathrm{T}$ cells with Drosophila cell transfectants as antigen presenting cells," Immunological Reviews, vol. 165, no. 1, pp. 249-265, 1998.

[30] I. Hwang, K. Kim, S. Choi, and M. Lomunova, "Potentiation of $\mathrm{T}$ cell stimulatory activity by chemical fixation of a weak peptide-MHC complex," Molecules and Cells, vol. 40, no. 1, pp. 24-36, 2017.

[31] Z. Cai, H. Kishimoto, A. Brunmark, M. R. Jackson, P. A. Peterson, and J. Sprent, "Requirements for peptide-induced $\mathrm{T}$ cell receptor downregulation on naive $\mathrm{CD} 8^{+} \mathrm{T}$ cells," Journal of Experimental Medicine, vol. 185, no. 4, pp. 641-652, 1997. 


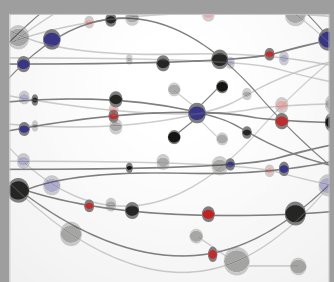

The Scientific World Journal
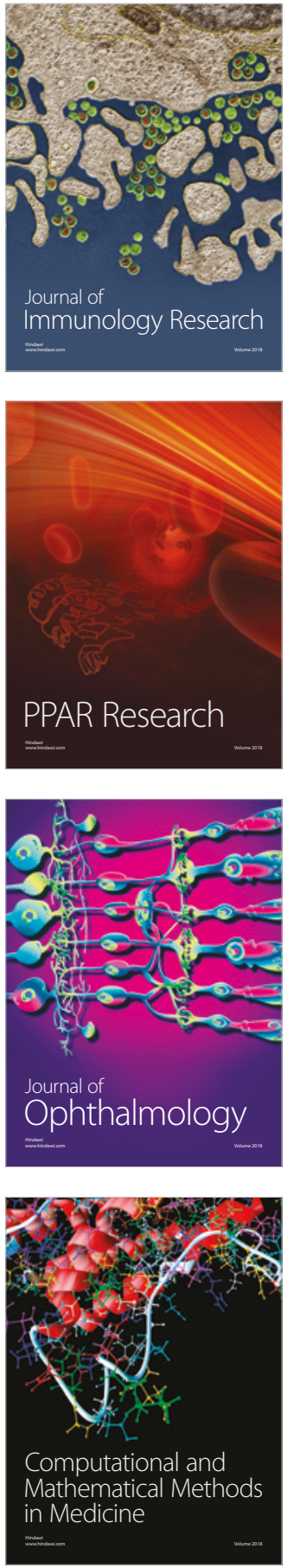

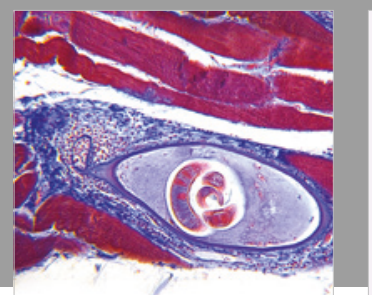

Gastroenterology Research and Practice

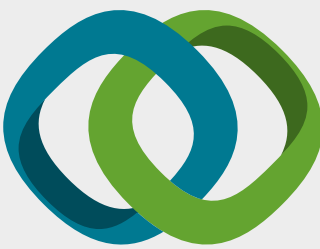

\section{Hindawi}

Submit your manuscripts at

www.hindawi.com
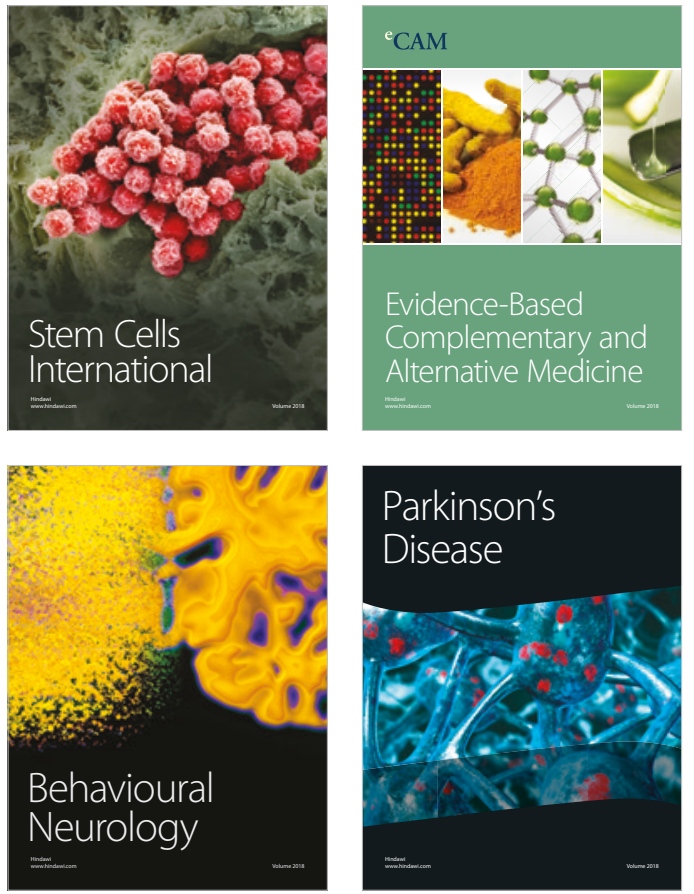

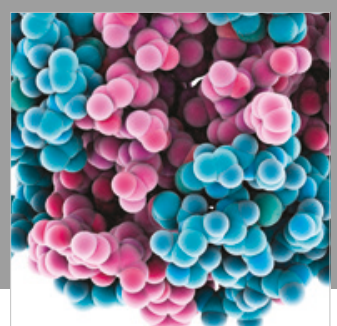

ournal of

Diabetes Research

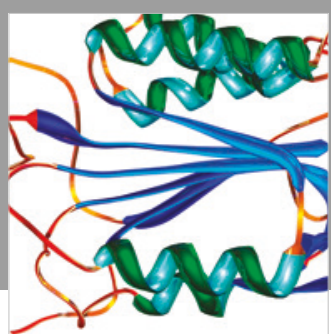

Disease Markers
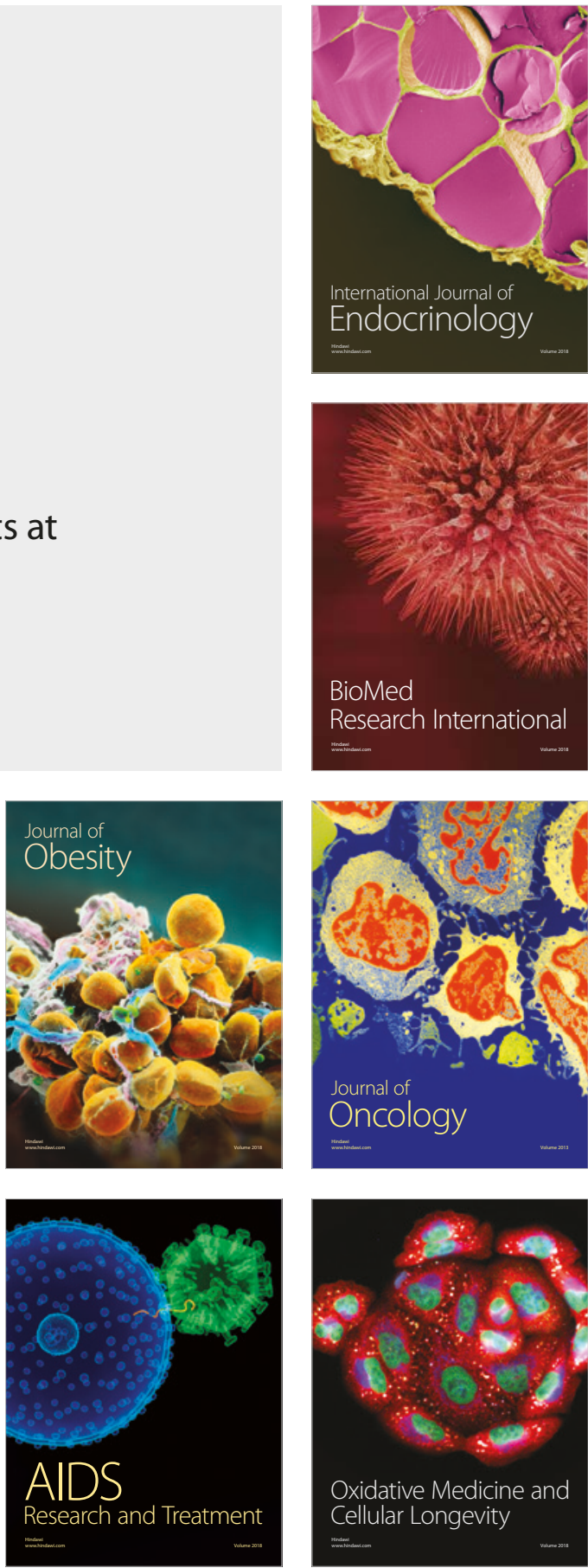